\title{
TU/e EmonONEN

\section{Prediction of the elasto-plastic post-buckling strength of uniformly compressed plates from the fictitious elastic strain at failure}

Citation for published version (APA):

Bakker, M. C. M., Rosmanit, M., \& Hofmeyer, H. (2009). Prediction of the elasto-plastic post-buckling strength of uniformly compressed plates from the fictitious elastic strain at failure. Thin-Walled Structures, 47(1), 1-13. https://doi.org/10.1016/j.tws.2008.04.004

DOI:

10.1016/j.tws.2008.04.004

Document status and date:

Published: 01/01/2009

Document Version:

Publisher's PDF, also known as Version of Record (includes final page, issue and volume numbers)

\section{Please check the document version of this publication:}

- A submitted manuscript is the version of the article upon submission and before peer-review. There can be important differences between the submitted version and the official published version of record. People interested in the research are advised to contact the author for the final version of the publication, or visit the DOI to the publisher's website.

- The final author version and the galley proof are versions of the publication after peer review.

- The final published version features the final layout of the paper including the volume, issue and page numbers.

Link to publication

\footnotetext{
General rights

- You may freely distribute the URL identifying the publication in the public portal. follow below link for the End User Agreement:

www.tue.nl/taverne

\section{Take down policy}

If you believe that this document breaches copyright please contact us at:

openaccess@tue.nl

providing details and we will investigate your claim.
}

Copyright and moral rights for the publications made accessible in the public portal are retained by the authors and/or other copyright owners and it is a condition of accessing publications that users recognise and abide by the legal requirements associated with these rights.

- Users may download and print one copy of any publication from the public portal for the purpose of private study or research.

- You may not further distribute the material or use it for any profit-making activity or commercial gain

If the publication is distributed under the terms of Article $25 \mathrm{fa}$ of the Dutch Copyright Act, indicated by the "Taverne" license above, please 


\title{
Prediction of the elasto-plastic post-buckling strength of uniformly compressed plates from the fictitious elastic strain at failure
}

\author{
M.C.M. Bakker*, M. Rosmanit, H. Hofmeyer

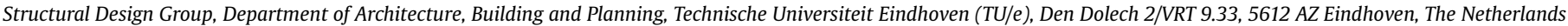

\section{A R T I C L E I N F O}

Article history:

Received 16 November 2007

Received in revised form

9 April 2008

Accepted 10 April 2008

Available online 2 June 2008

Keywords:

Plates

Compression

Post-buckling

Elastic

Strength

\begin{abstract}
A B S T R A C T
This paper discusses the use of the theory of elasticity to determine the post-buckling strength of uniformly loaded square simply supported thin (steel) plates with sinusoidal-shaped initial imperfections and longitudinal edges free to wave in plane. Based on the findings from a FEM parameter study two main types of failure are distinguished: edge failure and center failure. The parameters determining which failure mode occurs are explained using a simple two-strip model. To determine the elastic post-buckling behavior of plates a modified far post-buckling solution is proposed, which is simpler to use than the existing far post-buckling solutions reported in the literature, giving results with engineering accuracy for loads up to about three times the buckling load. It is shown that determining the post-buckling strength as the elastic load corresponding to first membrane yield (as is done in the effective width method) paradoxically gives reasonable results for plates failing by center failure, but very conservative results for plates failing by edge failure. For plates failing by edge failure a more accurate strength prediction is obtained by deriving empirical expressions for a fictitious elastic strain at failure.
\end{abstract}

(c) 2008 Elsevier Ltd. All rights reserved.

\section{Introduction}

This paper originates in an attempt to develop an effective width method to determine the strength of compression flanges of cold-formed deck sections, with an explicit influence of initial imperfections. It was expected that this could be done by using analytical solutions for the elastic initial post-buckling behavior of plates as given by Rhodes [1] determining the failure load as the elastic load corresponding to first membrane yield. For plates with stress-free longitudinal edges (free to wave in-plane) this load is relatively easy to calculate, because for these plates first membrane yield occurs at the center of the longitudinal edges, where only membrane stresses in the longitudinal direction are working.

To check the thus predicted failure loads finite element simulations were carried out (see Section 2), on square, simply supported plates with initial imperfections in the shape of the first buckling mode, and a reference slenderness $\lambda$ varying between 1 and $\sqrt{8}$, where

$\lambda=\sqrt{f_{y} / \sigma_{c r}}$

\footnotetext{
* Corresponding author. Tel.: +3140247 2331; fax: +31402450328.

E-mail address: M.C.M.Bakker@bwk.tue.nl (M.C.M. Bakker).
}

with $f_{y}$ being the yield stress and $\sigma_{c r}$ the buckling stress. This range was based on customary slenderness ratios of cold-formed deck sections. When the analytically predicted failure loads were compared to those determined with the finite element simulations, it was found that for plates with a reference slenderness $\lambda$ close to 1, and small initial imperfections, the predicted failure loads are slightly unconservative, while for plates with increasing slenderness, and increasing initial imperfections, they become more and more conservative (up to 30\%). In an attempt to understand why this is so, closer attention was paid to the failure modes of the plates in the finite element simulations. It was found (see Section 3) that four types of failure can be distinguished: failure by outer fiber yielding at the center of the plate (C-yielding), failure by membrane yielding of the (longitudinal) edges of the plate (E-yielding), failure by outer fiber yielding of the center followed by membrane yielding of the edge (CE-yielding), and failure by membrane yielding of the edge followed by outer fiber yielding at the center (EC-yielding). As will be discussed later these four types of failure can be reduced to two types of failure by defining edge failure (EF) as the failure mode of plates where membrane yielding at the longitudinal edge occurs before or without outer fiber yielding at the center, and center failure (CF) as the failure mode of plates where outer fiber yielding at the center occurs before or without membrane yielding at the longitudinal edge. In Section 3.3 it will be explained which parameters govern the occurrence of either mode, and in 


\begin{tabular}{|c|c|c|c|}
\hline \multicolumn{2}{|l|}{ Notation } & $F_{c e}$ & load carried by center strip \\
\hline$a$ & length of plate & $F_{e d}$ & load carried by edge strip \\
\hline$b$ & width of plate & $F_{u}$ & ultimate load of plate \\
\hline$b_{c e}$ & width of center strip & $F_{u ; \varepsilon f i c}$ & ultimate load of plate predicted by fictitious elastic \\
\hline$b_{e d}$ & width of edge strip & & strain method using $\varepsilon_{f i c ; u}$ \\
\hline$b_{e f}$ & effective width of plate & $F_{u ; \varepsilon f i c}^{C F}$ & ultimate load of plate predicted by fictitious elastic \\
\hline$b_{e f ; F u}$ & effective width of plate for strength & & strain method using $\varepsilon_{f i c ; u}^{C F}$ \\
\hline$b_{e f ; \varepsilon}$ & effective width of plate for stiffness & $F_{u ; f i c}^{E F}$ & ultimate load of plate predicted by fictitious elastic \\
\hline$b_{e f ; \sigma A}$ & $\begin{array}{l}\text { effective width of plate for maximum membrane } \\
\text { stress }\end{array}$ & $F_{u ; F E M}$ & $\begin{array}{l}\text { strain method using } \varepsilon_{f i c ; u}^{E F} \\
\text { ultimate load of plate determined by FEM simulation }\end{array}$ \\
\hline$f_{y}$ & yield strength & & yield load, equals $f_{y} b t$ \\
\hline$t$ & plate thickness & $K$ & buckling coefficient \\
\hline$u$ & in-plane shortening of plate & $\varepsilon$ & average in-plane strain: $u / a$ \\
\hline$u_{c r}$ & in-plane shortening of plate at buckling, equals $\varepsilon_{c r} a$ & $\varepsilon_{c r}$ & average in-plane strain at buckling, equals $\sigma_{c r} / E$ \\
\hline$w$ & $\begin{array}{l}\text { maximum out-of-plane deflection, occurring at center } \\
\text { of plate }\end{array}$ & $\begin{array}{l}\varepsilon_{f i c ; f m y} \\
\varepsilon_{f i c ; u}\end{array}$ & $\begin{array}{l}\text { fictitious elastic strain corresponding to } w_{f i c ; f m y} \\
\text { empirically predicted fictitious elastic strain at failure }\end{array}$ \\
\hline$w_{0}$ & maximum initial out-of-plane deflection, occurring at & $\varepsilon_{f i c ; u}^{C F}$ & $\varepsilon_{\text {fic } ; u}$ at center failure \\
\hline$w_{f i c ; F E M}$ & $\begin{array}{l}\text { center of plate } \\
\text { fictitious elastic out-of-plane displacement corre- }\end{array}$ & $\varepsilon_{f i c ; u}^{E F}$ & $\begin{array}{l}\varepsilon_{f i c ; u} \text { at edge failure } \\
\text { fictitious elastic stra }\end{array}$ \\
\hline$w_{f i c ; u}$ & $\begin{array}{l}\text { sponding to } F_{u ; F E M} \\
\text { fictitious elastic out-of-plane displacement corre- } \\
\text { sponding to } \varepsilon_{f i c ; u}\end{array}$ & $\begin{array}{l}\varepsilon_{\text {fic; } F E M} \\
\varepsilon_{y} \\
\eta\end{array}$ & $\begin{array}{l}\text { yield strain, equals } f_{y} / E \\
(w / t)^{2}-\left(w_{0} / t\right)^{2}\end{array}$ \\
\hline$w_{f i c ; f m y}$ & $\begin{array}{l}\text { fictitious elastic out-of-plane displacement corre- } \\
\text { sponding to first membrane yield }\end{array}$ & $\begin{array}{l}\eta_{\text {fic;fmy }} \\
\eta_{f i c ; u} \\
\eta_{\text {fic;FEM }}\end{array}$ & $\begin{array}{l}\left(w_{\text {fic;fmy }} / \mathrm{t}\right)^{2}-\left(w_{0} / t\right)^{2} \\
\left(w_{\text {fic;u }} / t\right)^{2}-\left(w_{0} / t\right)^{2} \\
\left(w_{\text {fic } ; F E M} / t\right)^{2}-\left(w_{0} / t\right)^{2}\end{array}$ \\
\hline$A$ & coefficient & $\lambda$ & reference slenderness: $\sqrt{f_{y} / \sigma_{c r}}$ \\
\hline$A_{u}, B_{u}$ & coefficients in expression to determine $u / u_{c r}$ & & Poisson's coefficient \\
\hline$A_{F}, B_{F}$ & coefficients in expression to determine $F / F_{c r}$ & $\sigma$ & average membrane stress $F /(b t)$ \\
\hline$A_{\sigma ; A}, B_{\sigma ; A}$ & coefficients in expression to determine $\sigma_{\mathrm{A}} / \sigma_{c r}$ & $\sigma_{\mathrm{A}}$ & membrane stress at point A (in $x$-direction of plate) \\
\hline & flexural rigidity factor & $\sigma_{c r}$ & buckling stress \\
\hline$E^{*} / E$ & $\begin{array}{l}\text { ratio of post-buckling to pre-bucking stiffness of } \\
\text { perfectly flat plate }\end{array}$ & $\begin{array}{l}\sigma_{c e} \\
\sigma_{e d}\end{array}$ & $\begin{array}{l}\text { stress in center strip } \\
\text { stress in edge strip }\end{array}$ \\
\hline
\end{tabular}

Section 3.4 it will be shown that the different failure modes can be explained qualitatively from a simple two-strip model originally proposed by Calladine [2] and modified by Bakker et al. [3].

It is difficult to predict the strength corresponding to the different failure modes by simple, purely analytical formulas. The elastic determination of first outer fiber yield at the center of the plate is possible (see for instance Mahendran [4]), but requires a lot of effort, because it is not only influenced by membrane stresses in the longitudinal direction, but also by membrane stresses in the transverse direction and by stresses caused by bending moments. Failure by membrane yielding of the edge is an elasto-plastic failure, but no accurate, simple analytical models are available yet to determine the elasto-plastic behavior of plates. Elasto-plastic failure loads might be determined as the point of intersection of elastic loading, and rigid-plastic unloading curves determined from an assumed yield line mechanism [5], but this type of calculations also requires a lot of calculation effort. This paper shows that by deriving empirical expressions for the fictitious elastic strain at failure, the post-buckling strength for both $\mathrm{CF}$ and $\mathrm{EF}$ can be determined from relatively simple analytical solutions for the elastic plate behavior of plates. Therefore, in Section 4 the elastic theory for the initial and far post-buckling behavior, available from literature is summarized. Initial post-buckling solutions have engineering accuracy for loads up to about twice the buckling load. Slender plates may fail at loads higher than twice the buckling load, making it necessary to use far post-buckling solutions for strength predictions. A modified far post-buckling theory is proposed which is simpler to use than the far post-buckling solutions described in the literature, giving results with engineering accuracy for loads up to about three times the buckling load. The results of these theories are compared to the results from the finite element simulations.

In Section 5.1, the fictitious elastic strains at failure are calculated. These are the elastic strains, which in a (purely elastic) modified far post-buckling calculation would result in a load equal to the elasto-plastic failure loads in the FEM simulations. In Section 5.2, empirical expressions are proposed to predict these fictitious elastic strains at failure, making a distinction between edge and center failure. The loads, calculated from the modified far post-buckling theory using the fictitious strains predicted by these empirical formulas are compared to the failure loads in the FEM simulations. In Section 6, it is explained how the modified far post-buckling theory and empirical formulas to determine the fictitious elastic strain at failure can be used in the effective width method. Also it is discussed whether it is necessary to include far post-buckling effects. Finally in Section 7 conclusions are summarized.

\section{Finite element simulations}

In this paper the post-buckling failure behavior of plates as shown in Fig. 1 is studied. All edges of the plate are simply supported $\left(u_{z}=0\right)$. The edges loaded by the compression force are forced to remain straight, but free to experience Poisson's contraction. The other two edges are free to wave in-plane, thus membrane stresses in the $y$-direction are equal to zero. These boundary conditions correspond to the boundary conditions 
a

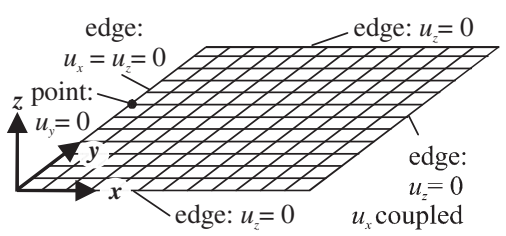

b

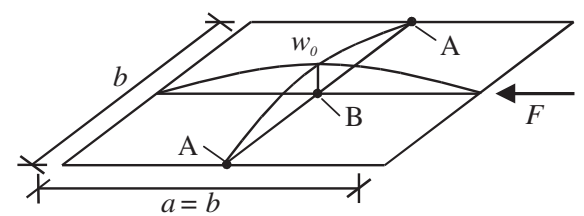

Fig. 1. Schematic view of numerical model: (a) boundary conditions and (b) initial imperfection, load, measures and location of points A and B.

Table 1

Considered values for buckling stress and resulting values for parameters depending on buckling stress

\begin{tabular}{|c|c|c|c|c|c|}
\hline$\sigma_{c r}\left(\mathrm{~N} / \mathrm{mm}^{2}\right)$ & $\lambda$ (dimensionless) & $b(\mathrm{~mm})$ & $b / t$ (dimensionless) & $F_{c r}(\mathrm{~N})$ & $u_{c r}(\mathrm{~mm})$ \\
\hline 300 & 1.000 & 35.2 & 50.3 & 7392.0 & $5.021 \times 10^{-2}$ \\
\hline 225 & 1.155 & 40.7 & 58.1 & 6410.3 & $4.361 \times 10^{-2}$ \\
\hline 150 & 1.414 & 49.8 & 71.1 & 5229.0 & $3.557 \times 10^{-2}$ \\
\hline 100 & 1.732 & 61.0 & 87.1 & 4270.0 & $2.905 \times 10^{-2}$ \\
\hline 75 & 2.000 & 70.4 & 100.6 & 3696.0 & $2.514 \times 10^{-2}$ \\
\hline 50 & 2.449 & 86.3 & 123.3 & 3020.5 & $2.055 \times 10^{-2}$ \\
\hline 37.5 & 2.828 & 99.6 & 142.3 & 2614.5 & $1.779 \times 10^{-2}$ \\
\hline
\end{tabular}

usually used for the modeling of compression flanges in thinwalled steel deck sections. The reason to choose these boundary conditions is that the research described in this paper is part of a research project on the strength of cold-formed deck sections subjected to the combined action of bending moment and concentrated load [6]. The concentrated load causes deformations of the compression flange, which may be quite large. Therefore it was decided to study the failure behavior of uniformly compressed plates with initial imperfections up to two times the plate thickness.

When a perfectly flat simply supported plate is subjected to uniaxial compression, the stress distribution is uniform over the plate, until the buckling load is reached. After buckling the stress distribution becomes non-uniform, both over the width $b$ and the length $a$ of the plate. For plates with initial imperfections the stress distribution is non-uniform from the onset of loading. In this paper, it is assumed that the plate has a sinusoidal initial imperfection, with the maximum imperfection $w_{0}$ occurring at the center of the plate (see Fig. 1).

In this paper the following results will be discussed as functions of the out-of-plane deflection $w$ at the center of the plate, where $w$ is the total out-of-plane deflection at the center of the plate, including the initial imperfection $w_{0}$ :

- the load $F$ or average stress $\sigma$ in $x$-direction:

$$
\sigma=\frac{F}{b t}
$$

- the axial shortening $u$ or the average strain $\varepsilon$ in $x$-direction:

$$
\varepsilon=\frac{u}{a}
$$

- membrane stresses $\sigma_{\mathrm{A}}$ in the $x$-direction at point A.

These results can be made dimensionless by using the buckling stress:

$\sigma_{c r}=\frac{K \pi^{2} D}{b^{2} t}$

from which we can define the buckling strain, $\varepsilon_{c r}$ :

$\varepsilon_{c r}=\frac{\sigma_{c r}}{E}$ the buckling shortening, $u_{c r}$ :

$u_{c r}=\varepsilon_{c r} a=\frac{\sigma_{c r} a}{E}$

and the buckling force, $F_{c r}$ :

$F_{c r}=b t \sigma_{c r}$

where $D$ is the plate flexural rigidity factor:

$D=\frac{E t^{3}}{12\left(1-v^{2}\right)}$

where $t$ is the plate thickness, $a$ and $b$ are the length and width of the plate (for a square plate $a=b$ ), $E$ is the modulus of elasticity, $K$ is the buckling coefficient (for a square plate $K=4$ ) and $v$ is Poisson's ratio.

According to Little [7], for two plates having the same values of $v, a / b, b / t, \sqrt{f_{y} / E}$ (or $f_{y} / \sigma_{c r}$ ) and $w_{0} / t$, but different values of $f_{y}, E$ and $w_{0} / b$, numerical analysis will predict precisely the same nondimensional load-shortening response. In the parameter study square plates were studied $(a=b)$ and the plate thickness and the material properties were kept constant: $t=0.7 \mathrm{~mm}, f_{y}=300$ $\mathrm{N} / \mathrm{mm}^{2}, v=0.3$, and $E=2.1 \times 10^{5} \mathrm{~N} / \mathrm{mm}^{2}$. The buckling stress $\sigma_{c r}$ was varied by varying the width $b$ of the plate. Table 1 gives an overview of the considered values for the buckling stress and the corresponding values for the reference slenderness $\lambda$, plate width $b, b / t$ ratio, buckling load $F_{c r}$ and buckling shortening $u_{c r}$. Each simulation has been performed once with linear-elastic material properties, and once with linear-elastic/ideal plastic material properties, using von Mises yield criterion. Thus a total of 7 elastic and 49 elasto-plastic geometrical non-linear simulations with the finite element program ANSYS 8.1 has been performed (for elastic behavior a calculation for only one critical stress is needed). In the model rectangular elements SHELL43 were used. The element has six degrees of freedom at each node: translations in the nodal $x$-, $y$ - and $z$-directions and rotations along the nodal axes. Calculations with this element are based on Mindlin plate theory. The deformation shapes are linear in both in-plane directions. The mesh density for each plate was $40 \times 40$ elements. The numerical analyses were performed for loads up to three times the buckling load. All boundary conditions, axis convention and the specific points on the plate are presented in Fig. 1. 

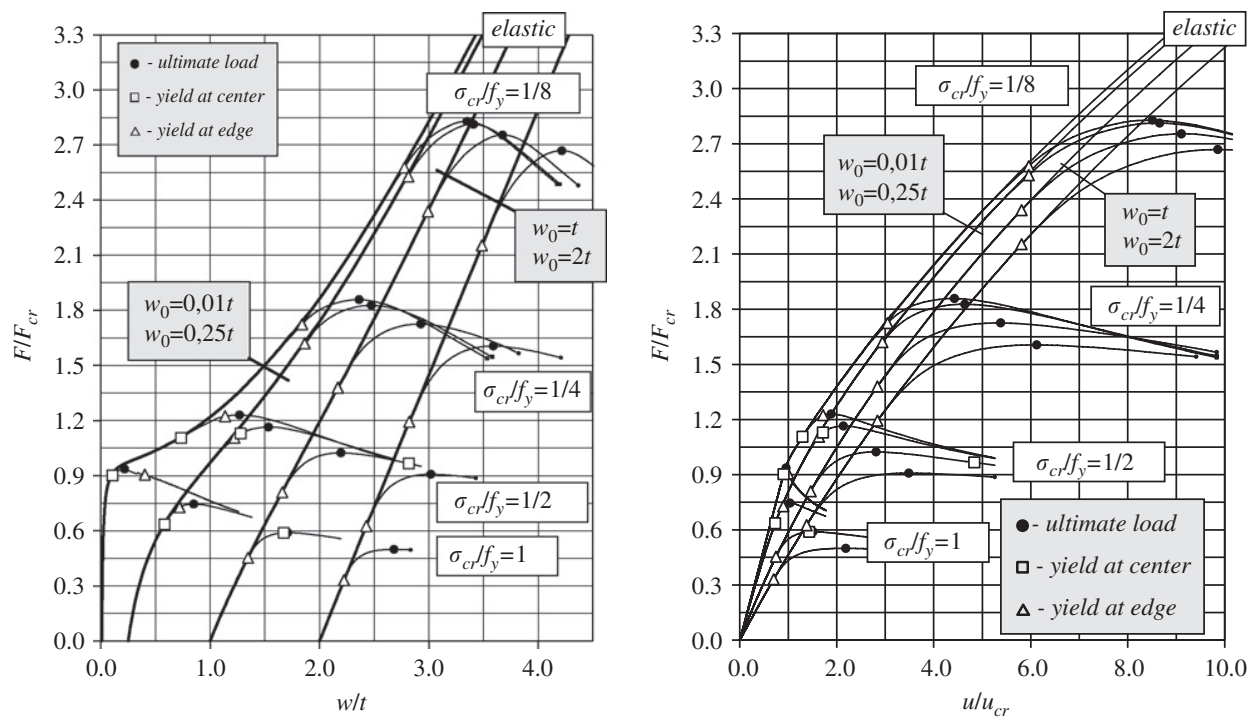

Fig. 2. Overview of selected elastic and elasto-plastic curves obtained from the FEM simulations.

\section{Failure modes occurring in finite element simulations}

\subsection{Introduction}

Fig. 2 shows selected elastic and elasto-plastic load-deflection curves obtained from the performed finite element simulations. In this figure the solid dots indicate the ultimate loads, the open squares indicate first outer fiber yield at the center of the plate (point $\mathrm{B}$ ), and the open triangles indicate first membrane yield at the center of the longitudinal edge (point A). These graphs indicate in what order center yielding and membrane yielding occur. This order forms the basis for classifying failure modes as edge or center failure modes. Fig. 3 shows the development of yield zones for the various failure modes. First yielding and second yielding indicated in this figure can be either outer fiber yielding at the center or membrane yielding at the edges. Outer fiber yielding at the corners is not included in defining first and second yielding, since it hardly influences the load-deflection behavior.

\subsection{Center failure}

Plates failing by CF can be distinguished into plates failing by center yielding of the plate (C-yielding) and plates failing by center yielding followed by edge yielding (EC-yielding). In plates failing by C-yielding, first yield occurs in the outer fibers of the center of the plate (point $\mathrm{B}$ ), resulting in an immediate deviation of the elasto-plastic load-deformation behavior from the elastic behavior. Next the outer fibers in an area near the corners of the plate start yielding. First membrane yield (at point $A$ of the longitudinal edge) occurs after failure, and thus cannot influence the failure load. Failure by C-yielding results in failure with very little elasto-plastic reserve. The failure loads may be smaller than the (fictitious) elastic load corresponding to first membrane yield at the longitudinal edge. Failure by CE-yielding resembles failure by C-yielding, except that the plate has some elasto-plastic reserve after center yielding and fails only when in the longitudinal edge membrane yielding starts.

\subsection{Edge failure}

Plates failing by EF can be distinguished in plates failing by edge yielding (E-yielding) and plates failing by edge yielding followed by center yielding (EC-yielding). In plates failing by E-yielding first yield occurs at the outer fibers of the corner. This outer fiber yield has hardly any influence on the loaddeflection behavior of the plate. The elasto-plastic load-deflection curve starts to deviate from the elastic load-deflection curve only after first membrane yield (at point $A$ of the longitudinal edge). Failure is not at first membrane yield, but after some membrane yielding of the plate edges, at average strains larger than the yield strain. The failure loads may be significantly larger than the (fictitious) elastic load corresponding to first membrane yield at the longitudinal edge. Failure by EC-yielding resembles failure by E-yielding, except that additional center yielding occurs before failure, resulting in smaller strains at failure and a steeper unloading behavior after failure.

\subsection{Parameters determining failure modes}

Table 2 gives an overview, which failure modes occurred in the FEM simulations. It shows that the more slender plates $(\lambda \geqslant 2)$ always fail by E-yielding, regardless of the imperfection. For more stocky plates, $(\lambda \leqslant 1.155)$ the failure mode changes from C-yielding, to CE-yielding, EC-yielding and E-yielding with increasing initial imperfections. For plates with a reference slenderness $\lambda=1.414$, the same sequence of failure modes is found, except that the failure by C-yielding does not occur, and that failure by EC-yielding is found for smaller imperfections than in the more slender plates. It is thought that for plates with a very small imperfection $\left(w_{0} / t=0.01\right)$, the failure mode changes from C-yielding, to CE-yielding, EC-yielding and E-yielding by increasing the slenderness. In Table 2 the failure by EC-yielding is missing for plates with an imperfection $w_{0} / t=0.01$, but for plates with an imperfection $w_{0} / t=0.25$, this failure mode is found between the CE-yielding and E-yielding failure modes.

The sequence in occurring failure modes suggests that yielding at the first location is more decisive for the failure mode than yielding at the second location although one might think that the latter should be regarded as the final cause of failure. Therefore it seems justified to reduce the four modes to two modes: CF incorporating modes C-yielding and CE-yielding, and EF incorporating modes EC-yielding and E-yielding. 


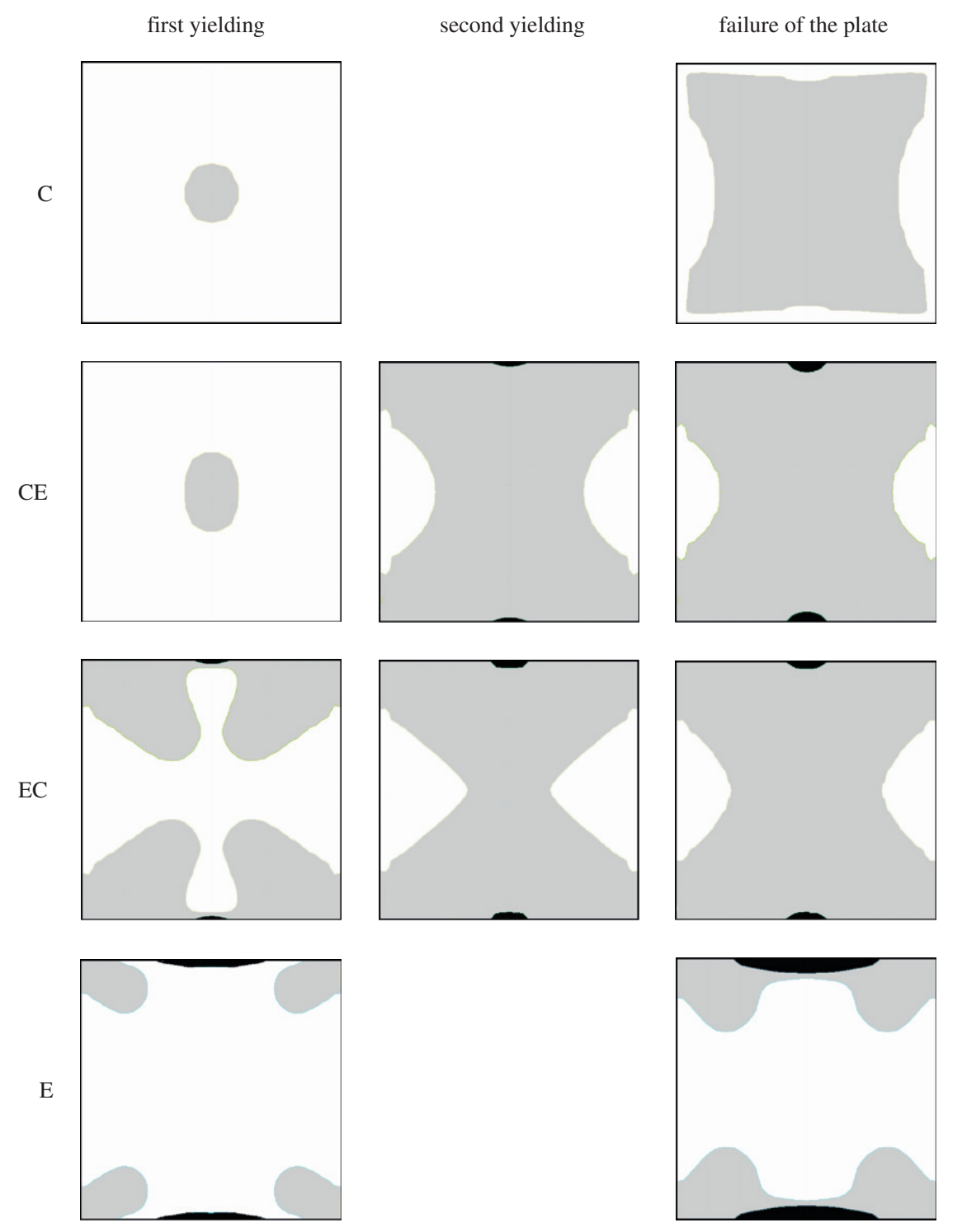

Fig. 3. Figures showing yield locations in C-, CE-, EC- and E-yielding failure modes (white—no yielding, gray—outer fiber yielding and black—membrane yielding).

Table 2

Failure modes observed in FEM parameter study; the bold values represent center failure (CF) according to Mahendran's criterion [4]

\begin{tabular}{|c|c|c|c|c|c|c|c|c|}
\hline \multicolumn{2}{|c|}{$\sigma_{c r} \mid f_{y}$} & 1 & $3 / 4$ & $1 / 2$ & $1 / 3$ & $1 / 4$ & $1 / 6$ & $1 / 8$ \\
\hline \multicolumn{2}{|l|}{$\lambda$} & 1.000 & 1.155 & 1.414 & 1.732 & 2.000 & 2.449 & 2.828 \\
\hline$\overline{w_{0}}$ & $0.01 t$ & C & C & CE & $E$ & $E$ & $E$ & $E$ \\
\hline$w_{0}$ & $0.10 t$ & CE & CE & CE & $E$ & $\mathrm{E}$ & E & $\mathrm{E}$ \\
\hline$w_{0}$ & $0.25 t$ & CE & CE & EC & $\mathrm{E}$ & $\mathrm{E}$ & E & $\mathrm{E}$ \\
\hline$w_{0}$ & $0.50 t$ & EC & EC & EC & $E$ & $E$ & $\mathrm{E}$ & $E$ \\
\hline$w_{0}$ & $1.00 t$ & $E$ & $E$ & $E$ & $E$ & $E$ & $\mathrm{E}$ & $\mathrm{E}$ \\
\hline$w_{0}$ & $1.50 t$ & $\mathrm{E}$ & $\mathrm{E}$ & E & $\mathrm{E}$ & $\mathrm{E}$ & $\mathrm{E}$ & $\mathrm{E}$ \\
\hline$w_{0}$ & $2.00 t$ & $\mathrm{E}$ & $\mathrm{E}$ & E & $E$ & $E$ & $\mathrm{E}$ & $E$ \\
\hline
\end{tabular}

C: center yielding; CE: center yielding followed by edge yielding; E: edge yielding; EC: edge yielding followed by center yielding.

According to Mahendran [4], center yielding of the plate will occur before edge membrane yielding if

$\frac{w_{0}}{t} \leqslant 0.67+0.086 S-0.081 S^{2}$ where $S$ is a slenderness parameter:

$S=\frac{b}{t} \sqrt{\frac{f_{y}}{E}}$

Using Eqs. (4) and (8), and taking $v=0.3$ it can be shown that

$S=1.901 \lambda$

This formula agreed well with the performed finite element simulations. In the few cases where Mahendran's formula did not agree with the FEM results (see Table 2), edge yielding and center yielding occurred almost at the same time.

\subsection{Explanation by two-strip model}

In [3] it was shown that the two-strip model can give an accurate description of elastic post-buckling behavior. Here it will be shown that the two-strip model can also be used to give a qualitative explanation of the occurring failure modes. In the twostrip model $[2,3,8]$ there are two edge strips and one center strip. The load carried by the plate is the sum of the loads carried by 
a

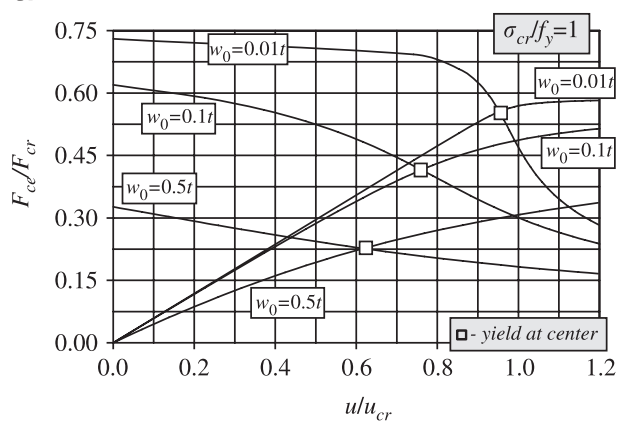

b

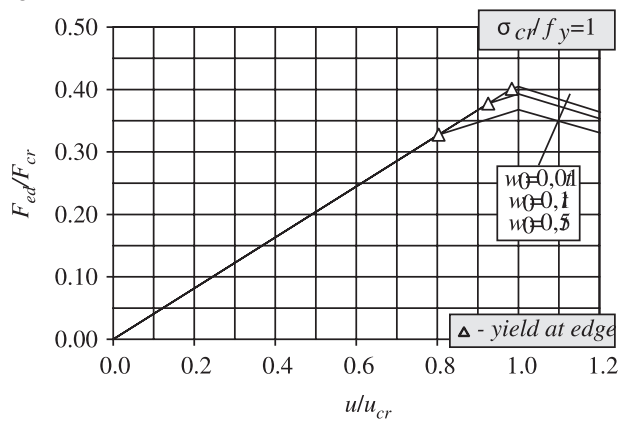

C

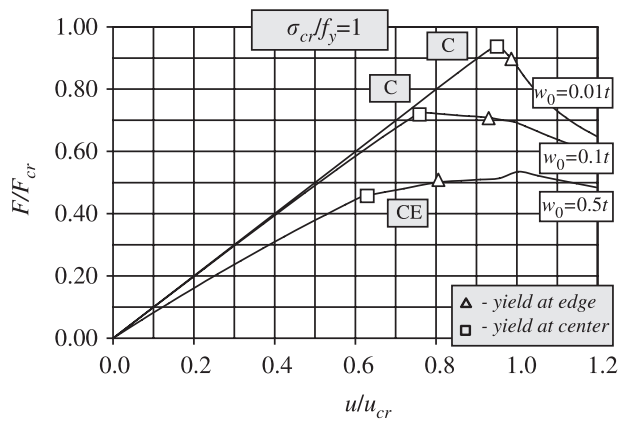

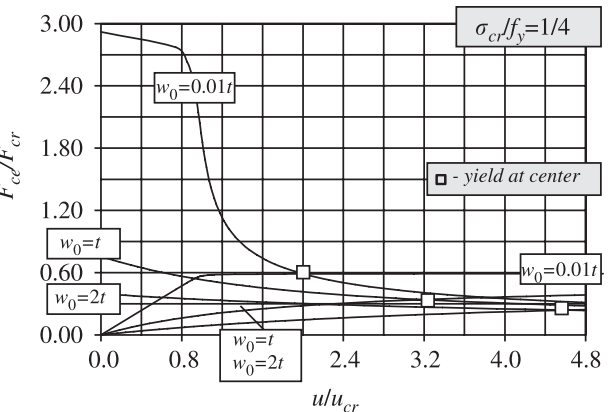
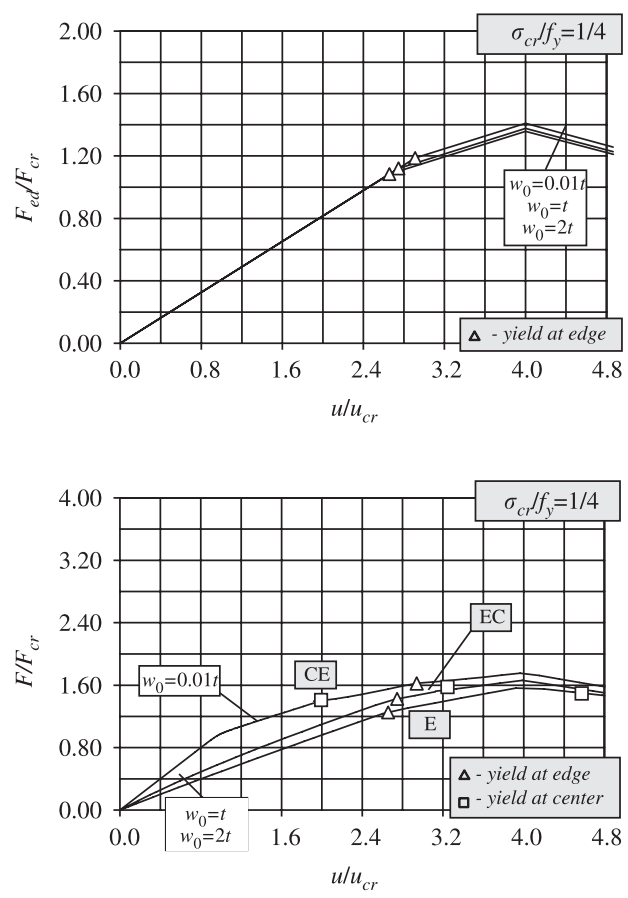

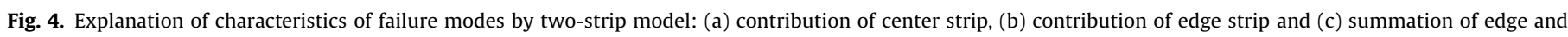
center strip contributions.

the separate strips:

$F=F_{e d}+F_{c e}=b_{e d} t \sigma_{e d}+b_{c e} t \sigma_{c e}$

where $F_{e d}$ and $F_{c e}$ are the loads carried by the edge strips, respectively, the center strip, $b_{e d}$ and $b_{c e}$ are the widths of the edge strip, respectively, the center strip and $\sigma_{e d}$ and $\sigma_{c e}$ are the stresses in the edge strips, respectively, the center strip.

If the plate behavior is elastic then the center strip is assumed to behave like a classical Euler column, that is, the stresses in it can be calculated as

$\sigma_{c e}=\left(1-\frac{w_{0}}{w}\right) \sigma_{c r}$

where $\sigma_{c r}$ is the buckling stress of the plate (not of the strip). The two edge strips always remain straight and together constitute a single element of the system. The stresses in the edge strips are proportional to the in-plane shortening $u$ of the plate:

$\sigma_{e d}=E u / a=E \varepsilon$

The only compatibility requirement taken into account is that the center strip and edge strips experience the same in-plane shortening $u$. It can be derived [3] that the relation between the in-plane shortening $u$ and the maximum out-of-plane deflection $w$ of the modeled plate is given by

$u=\frac{\sigma_{c e} a}{E}-\frac{C_{w} \pi^{2}\left(w^{2}-w_{0}^{2}\right)}{4 a}$

with

$C_{w}=\frac{b}{2\left(b-b_{e d}\right)}$

The width of the edge strip can be determined from the ratio $E^{*} / E$ of post-buckling to pre-buckling stiffness of the perfectly flat plate, since it can be shown that for the two-strip model:

$\frac{E^{*}}{E}=\frac{b_{e d}}{b}$

Eqs. (15) and (17) are valid only in the initial post-buckling range. They can be modified to be valid also in the far postbuckling range, as explained in [8]. For the qualitative discussion in this section the difference between initial and far post-buckling formulations (see also Section 4) will be ignored for simplicity.

The occurrence of different failure modes can be understood from the two-strip model by assuming that the center and edge strip have different failure mechanisms. It is proposed that failure of the center strip can be determined as the point of intersection of the elastic curve, and a rigid-plastic curve (see Fig. 4a). 
The rigid-plastic curve can be determined by assuming a local plastic mechanism with one yield line at the center of the center strip, perpendicular to its longitudinal edges. The following formulas can then be derived:

$\sigma_{c e}=\frac{m_{p ; r e d}}{w t}$

where $m_{p ; r e d}$ is the reduced plastic moment capacity per unit width of the center strip, which is reduced due to the presence of a normal force $\sigma_{c e} t$ per unit width:

$m_{p ; r e d}=m_{p}\left(1-\left(\frac{\sigma_{c e} t}{n_{p}}\right)^{2}\right)$

with

$m_{p}=\frac{1}{4} t^{2} \frac{2}{\sqrt{3}} f_{y}$

$n_{p}=t \frac{2}{\sqrt{3}} f_{y}$

where $m_{p}$ is the plastic moment capacity per unit width of the center strip and $n_{p}$ is the plastic normal force capacity per unit width of the center strip. The factor $2 / \sqrt{3}$ in Eqs. (20) and (21) arises from the assumption that no strain rates occur in the length direction of the yield line. Inserting Eq. (19) into Eq. (18) and solving for $\sigma_{c e}$ results in

$\sigma_{c e}=\frac{-n_{p}^{2} w+n_{p} \sqrt{4 m_{p}^{2}+n_{p}^{2} w^{2}}}{2 m_{p}}$

It is assumed that relation between $u$ and $w$ is the same for elastic and elasto-plastic plate behavior (see Eq. (15)).

To model failure of the edge strip (see Fig. 4b) it is proposed that the edge strip remains elastic until the average strain of the plate equals the fictitious elastic average strain $\varepsilon_{\text {fic; fmy }}$ corresponding to first membrane yield at the longitudinal edge (the determination of this strain will be discussed in Section 5.1). After first membrane yield of the edge strip, the stiffness of the edge strip decreases. This is modeled (rather arbitrarily) by assuming that after first membrane yield of the edge the stress in the edge strip can be calculated as

$\sigma_{e d}=E \varepsilon_{f i c: f m y}+0.5 E\left(\varepsilon-\varepsilon_{f i c: f m y}\right)$

It is furthermore assumed that failure occurs at an average strain corresponding to the yield strain

$\varepsilon_{y}=\frac{f_{y}}{E}$

Note that many of these assumptions are disputable. They will not be discussed here since the object goal is not to give an accurate quantitative description of the post-buckling strength, but only to provide insight in the occurring failure modes.

Fig. 4c shows the resultant behavior if the contributions of the edge strip and center strip are added, for a plate with a reference slenderness $\lambda=1$ and a plate with a reference slenderness $\lambda=2$. For the first plate $f_{y}=\sigma_{c r}$ and $u_{y}=u_{c r}$, for the second plate $f_{y}=4 \sigma_{c r}$ and $u_{y}=4 u_{c r}$. This figure shows that for plates with a reference slenderness close to 1 , and very small imperfections, failure of the plate is due to C-yielding. The smaller the imperfection is, the steeper is the reduction of load carrying capacity after failure. For plates with slightly larger initial imperfections or a slightly larger slenderness, the decrease in load carrying capacity of the center strip may be compensated by the still increasing load carrying capacity of the edge strip, thus resulting in failure due to $\mathrm{CE}$-yielding. When the imperfections or plate slenderness increase further, failure of the center strip will occur at strains larger than the elastic strain corresponding to first membrane yield, but at strains smaller than the yield strain, resulting in failure by EC-yielding. Finally the imperfections or plate slenderness may become so large that the center strip will fail only at strains larger than the yield strain, resulting in failure by E-yielding.

\subsection{Discussion}

As far as the authors know the described failure modes have not been distinguished explicitly before. Calladine [2] mentioned the possibility of different failure modes. He proposed a two-strip model (which was modified by the authors to the strip model described in Section 3.5) to determine the failure load of uniformly compressed plates with the longitudinal edges kept straight, assuming that failure occurs at average strains larger than the yield strain, when outer fiber yield occurs in the center of the plate. He noted that failure at strains smaller than the yield strain might occur for plates with $\lambda=1$ and very small initial imperfections. Calladine [2] furthermore commented that Walker and Murray [9] had taken a different view on the cause of failure, proposing a design formula based on first yield at the center of the longitudinal edge, "with complete indifference to the flexural stresses at the center of the plate, and to the unstable behavior which occurs in consequence."

Calladine [2] was aware of the difference between plates with longitudinal edges kept straight, where the membrane stresses in $x$-direction are uniform over the length of the plate, and plates with stress-free longitudinal edges, where high localized membrane stresses in $x$-direction occur at the center of the longitudinal edge. He noted that these stresses might be responsible for the choice of final failure mode between the roof mechanism and the flip-disc mechanism, observed experimentally in the collapse of steel tubes in compression. This hypothesis was confirmed by Mahendran [4], and it is interesting to see that Eq. (9) developed by Mahendran to predict whether the roof or flip-disc mechanism will occur, can also be used to predict whether the plate will fail by EF or CF. Note, however, that the edge failure and center failure do not have a direct relation to the roof and flip-disc mechanism. First, no yield line mechanism was observed at failure in the performed finite element simulations. Second, a flip-disc mechanism is incompatible with the symmetrical deformation mode at failure (more or less corresponding to the symmetrical shape of initial imperfections).

\section{Modeling elastic behavior}

\subsection{Initial post-buckling solution}

The elastic post-buckling behavior of thin plates with initial imperfections is governed by Marguerre's equations. Approximate analytical solutions for these equations can be found by postulating a shape for the out-of-plane deflections $w$. At loads below about twice the buckling load the assumption of an unchanging buckled form gives results of engineering accuracy. According to Rhodes [1] the solution based on an unchanging sinusoidal deflection shape can be described by the following equations:

$$
\begin{aligned}
& \frac{F}{F_{c r}}=\frac{\sigma}{\sigma_{c r}}=\left(1-\frac{w_{0}}{w}\right)+A_{F} \eta \\
& \frac{u}{u_{c r}}=\frac{\varepsilon}{\varepsilon_{c r}}=\left(1-\frac{w_{0}}{w}\right)+A_{u} \eta \\
& \frac{\sigma_{A}}{\sigma_{c r}}=\left(1-\frac{w_{0}}{w}\right)+A_{\sigma ; A} \eta
\end{aligned}
$$


Table 3

Table of coefficients $A$ and $B$

\begin{tabular}{clll}
\hline Coefficients & $\begin{array}{l}\text { Initial post- } \\
\text { buckling } \\
\text { solution }\end{array}$ & $\begin{array}{l}\text { Far post-buckling } \\
\text { solution (in format } \\
\text { modified far post- } \\
\text { buckling solution) }\end{array}$ & $\begin{array}{c}\text { Modified far post- } \\
\text { buckling solution }\end{array}$ \\
\hline$F / F_{c r}$ & & & \\
$A_{F}$ & 0.2356 & 0.2149 & 0.2356 \\
$B_{F}$ & 0 & $-0.4283 \times 10^{-3}$ & $-0.3137 \times 10^{-2}$ \\
$u / u_{c r}$ & 0.5775 & 0.5559 & 0.5775 \\
$A_{u}$ & 0 & $0.1257 \times 10^{-1}$ & $0.7799 \times 10^{-2}$ \\
$B_{u}$ & & & 0.9062 \\
$\sigma_{A} / \sigma_{c r}$ & 0.9062 & 0.8429 & $-0.2608 \times 10^{-2}$ \\
$A_{\sigma ; A}$ & 0 & $0.9572 \times 10^{-2}$ & \\
$B_{\sigma ; A}$ & & &
\end{tabular}

with

$A_{F}=\frac{A}{K} \frac{E^{*}}{E}, \quad A_{u}=\frac{A}{K}, \quad A_{\sigma ; A}=\frac{A}{K} \frac{E^{*}}{E} / \frac{\partial \sigma}{\partial \sigma_{\mathrm{A}}}$

where

$\eta=\left(\frac{w}{t}\right)^{2}-\left(\frac{w_{0}}{t}\right)^{2}$

$A$ is a coefficient, $E^{*} / E$ is the ratio of the pre-buckling to postbuckling stiffness for a perfectly flat plate without initial imperfections and the ratio $\partial \sigma / \partial \sigma_{\mathrm{A}}$ is a partial variation of the average stress $\sigma$. Rhodes [1] gives values for the coefficients $K, A$, $E^{*} / E$ and $\partial \sigma / \partial \sigma_{\mathrm{A}}$ depending on the ratio $e=a / b$ of the buckle half width $a$ and the plate width $b$ of the plate. For the case $e=1$ (square plates), he gives the following values for a simply supported plate with stress-free unloaded edges:

$K=4, \quad A=2.31, \quad \frac{E^{*}}{E}=0.408, \quad \frac{\partial \sigma}{\partial \sigma_{A}}=0.26$

These values are valid for Poisson's ratio $v=0.3$. The resulting $A_{F}, A_{u}$ and $A_{\sigma ; \mathrm{A}}$ values are given in Table 3.

\subsection{Far post-buckling solution}

For loads larger than about twice the buckling load the changes in the buckling form must be accounted for. Williams and Walker [10] gave an explicit solution for the elastic far post-buckling analysis of compressed plates. The format of their expressions is based on the perturbation approach, but the value of the constants in these expressions has been determined from numerical simulations (using the finite difference method). Their solution takes the following form:

$A_{w}^{W \& W} \phi+B_{w}^{W \& W} \phi^{3}=\sqrt{\eta}$

in which

$\phi=\sqrt{\frac{F}{F_{c r}}-1+\frac{w_{0}}{w}}$

$\frac{u}{u_{c r}}=\frac{F}{F_{c r}}+A_{u}^{W \& W} \eta+B_{u}^{W \& W} \eta^{2}$

$\frac{\sigma_{\mathrm{A}}}{\sigma_{c r}}=\frac{F}{F_{c r}}+A_{\sigma ; A}^{W \& W} \eta+B_{\sigma ; A}^{W \& W} \eta^{2}$

For a square plate with simply supported edges, subjected to uniaxial compression with the unloaded edges stress free, Williams and Walker [10] give the following values for the coefficients (valid for $v=0.3$ ):

$A_{w}^{W \& W}=2.157$ and $B_{w}^{W \& W}=0.010$

$A_{u}^{W \& W}=0.341$ and $B_{u}^{W \& W}=0.013$

$A_{\sigma A}^{W \& W}=0.628$ and $B_{\sigma A}^{W \& W}=0.010$

\subsection{Modified far post-buckling solution}

It was found that Eqs. (32)-(34) can be rewritten in a format similar to Eqs. (25)-(27). Therefore first the coefficient $\phi$ is solved from Eq. (32) (using the Mathematica 5.2 program), resulting in

$\phi=\frac{-2.71765+26.4567 C^{2}}{C}$

with

$C=(0.0027 \sqrt{\eta}+0.0027 \sqrt{148.678+\eta})^{1 / 3}$

From Eqs. (32), (38) and (39) the load $F$ can be solved:

$\frac{F}{F_{c r}}=\left(\frac{-2.71765+26.4567 C^{2}}{C}\right)^{2}+1-\frac{w_{0}}{w}$

Using a power series expansion for $F / F_{c r}$ about the point $\eta=0$ and leaving out negligible small terms, this equation can be further simplified to get

$\frac{F}{F_{c r}}=\frac{\sigma}{\sigma_{c r}}=\left(1-\frac{w_{0}}{w}\right)+A_{F} \eta+B_{F} \eta^{2}$

Using Eq. (41), Eqs. (33) and (34) can be written as

$\frac{u}{u_{c r}}=\frac{\varepsilon}{\varepsilon_{c r}}=\left(1-\frac{w_{0}}{w}\right)+A_{u} \eta+B_{u} \eta^{2}$

$\frac{\sigma_{A}}{\sigma_{c r}}=\left(1-\frac{w_{0}}{w}\right)+A_{\sigma ; A} \eta+B_{\sigma ; A} \eta^{2}$

The resulting $A$ and $B$ values, derived from the coefficients $A^{W \& W}$ and $B^{W \& W}$, are given in Table 3, under far post-buckling solution.

In the perturbation approach by Williams and Walker [10], both the coefficients $A^{W \& W}$ and $B^{W \& W}$ were determined from the results of numerical solutions. In this paper it is proposed to take the coefficients $A$ equal to the coefficients determined in the initial post-buckling solution of the Marguerre equations, and fitting the coefficient $B$ to the results of numerical simulations, using the format of Eqs. (41)-(43) instead of (31)-(34). The resulting coefficients are given in Table 3 , under modified far post-buckling solution. The coefficients $B$ where fitted for $w_{0}=t$ and $F / F_{c r}=3.0$, because it was found that these specific values yield the best results. For more results see Rosmanit and Bakker [11]. The advantage of the modified far post-buckling solution to the far post-buckling solution given by Williams and Walker [10] is that the equations of the modified far post-buckling solution are easier to use. Also the modified far post-buckling solution is more consistent, since for small deflections the modified far postbuckling solution will converge to the initial post-buckling solution, while the far post-buckling solution will not.

\subsection{Comparison of results}

Graphical and numerical comparisons of a representative selection of results are shown in Figs. 5-7. It can be seen that the modified far post-buckling solution gives the most accurate results for the ratios $F / F_{c r}$ and $u / u_{c r}$. For small imperfections the initial post-buckling solution gives results within $5 \%$ error for loads up to about twice the buckling load, but for large initial 


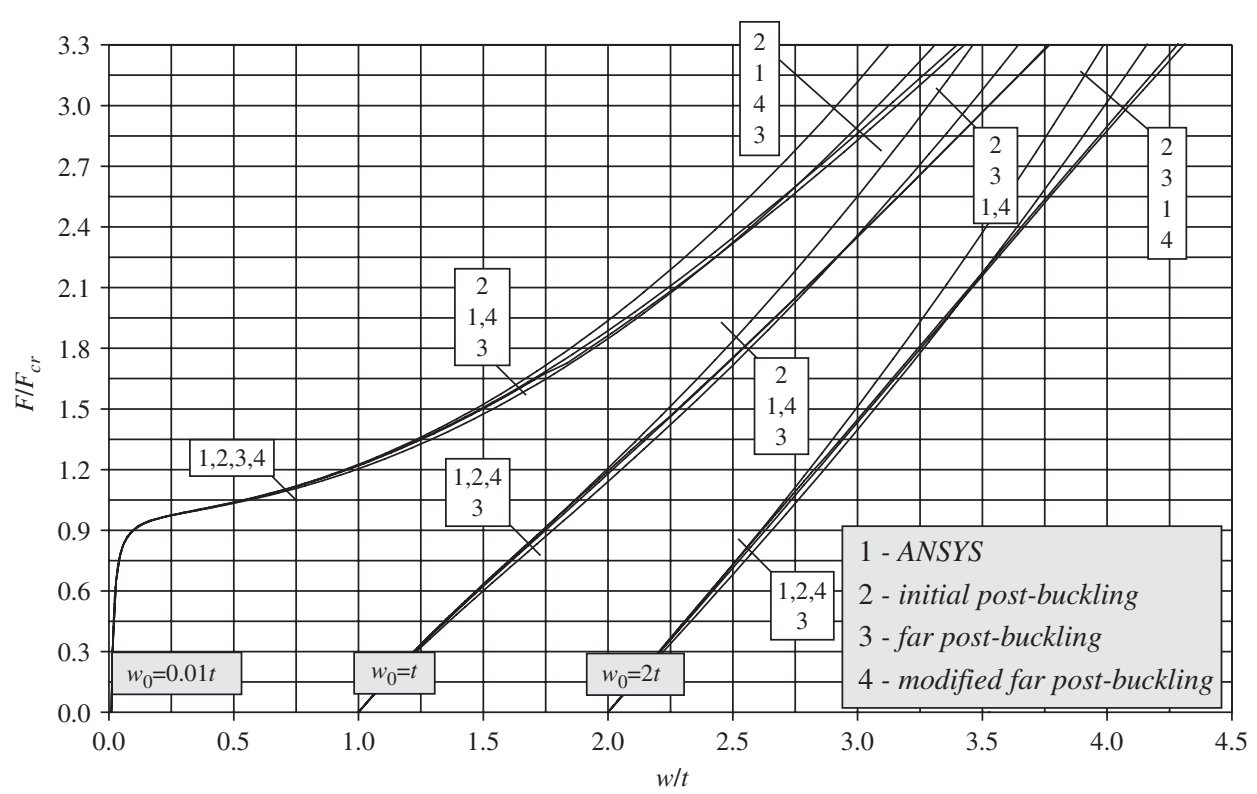

Fig. 5. Overview of selected elastic curves obtained from the FEM simulations and initial post-buckling, far post-buckling and modified far post-buckling solutions.

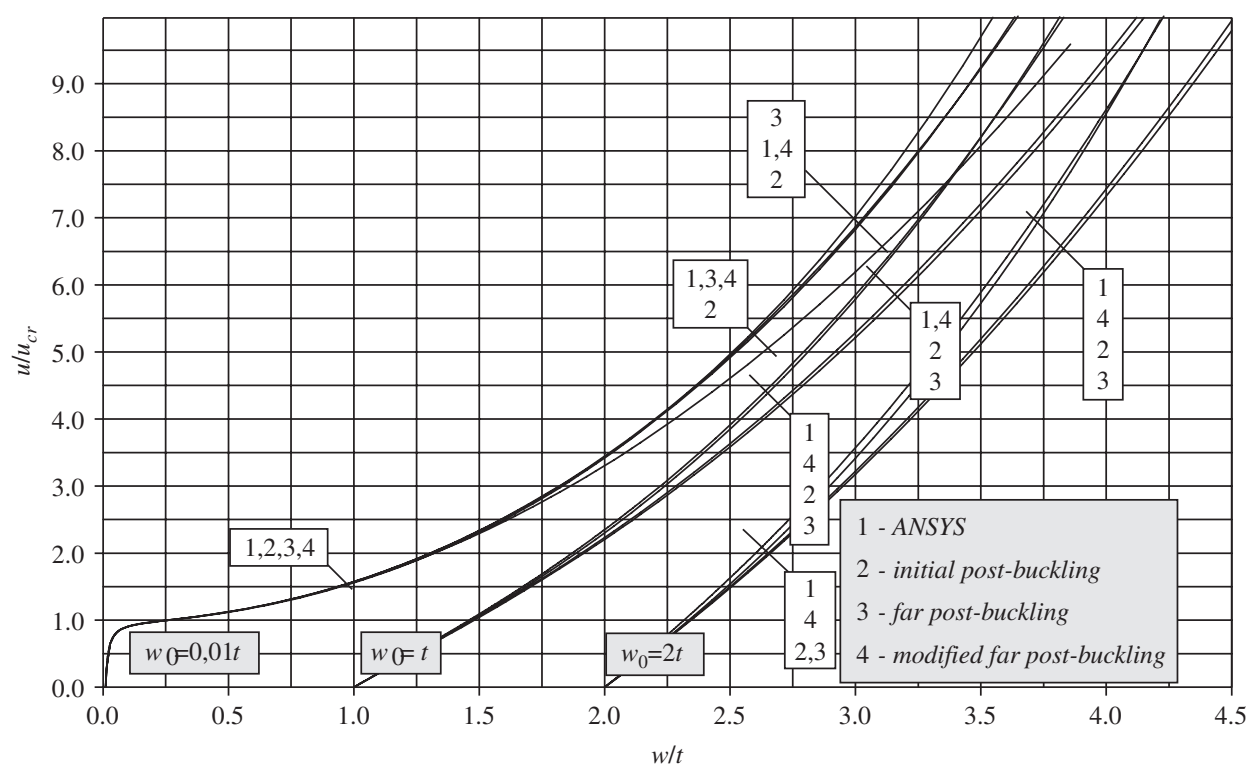

Fig. 6. Overview of selected elastic curves obtained from the FEM simulations and initial post-buckling, far post-buckling and modified far post-buckling solutions.

imperfections the $5 \%$ error occurs at lower loads. With respect to the membrane stresses $\sigma_{\mathrm{A}}$ it is surprising to see that the initial post-buckling solution gives better results than the far postbuckling solution, even for large initial imperfections and/or large deflections. The modified far post-buckling solution is almost identical to the initial post-buckling solution, since the coefficient $B_{\sigma ; A}$ is very small.

\section{Prediction of failure loads}

\subsection{Fictitious elastic strains at failure and first membrane yield}

To check whether it would be possible to use the modified far post-buckling solution for the prediction of the post-buckling strength of plates, the fictitious elastic strains $\varepsilon_{\text {fic;FEM }}$ corresponding to the elasto-plastic failure loads $F_{u ; F E M}$ determined from the FEM simulations as shown in Table 4 were calculated. This can be done as follows. Eq. (41) describes the non-linear-elastic relationship between force and out-of-plane displacement. Now for the force, the ultimate load $F_{u ; F E M}$ as predicted by the FEM simulations can be used, and the fictitious displacement $w_{\text {fic;FEM }}$ can be solved from

$\frac{F_{u ; F E M}}{F_{c r}}=\left(1-\frac{w_{0}}{w_{f i c ; F E M}}\right)+A_{F} \eta_{f i c ; F E M}+B_{F} \eta_{f i c ; F E M}^{2}$

where

$\eta_{f i c ; F E M}=\left(\frac{w_{f i c ; F E M}}{t}\right)^{2}-\left(\frac{w_{0}}{t}\right)^{2}$ 


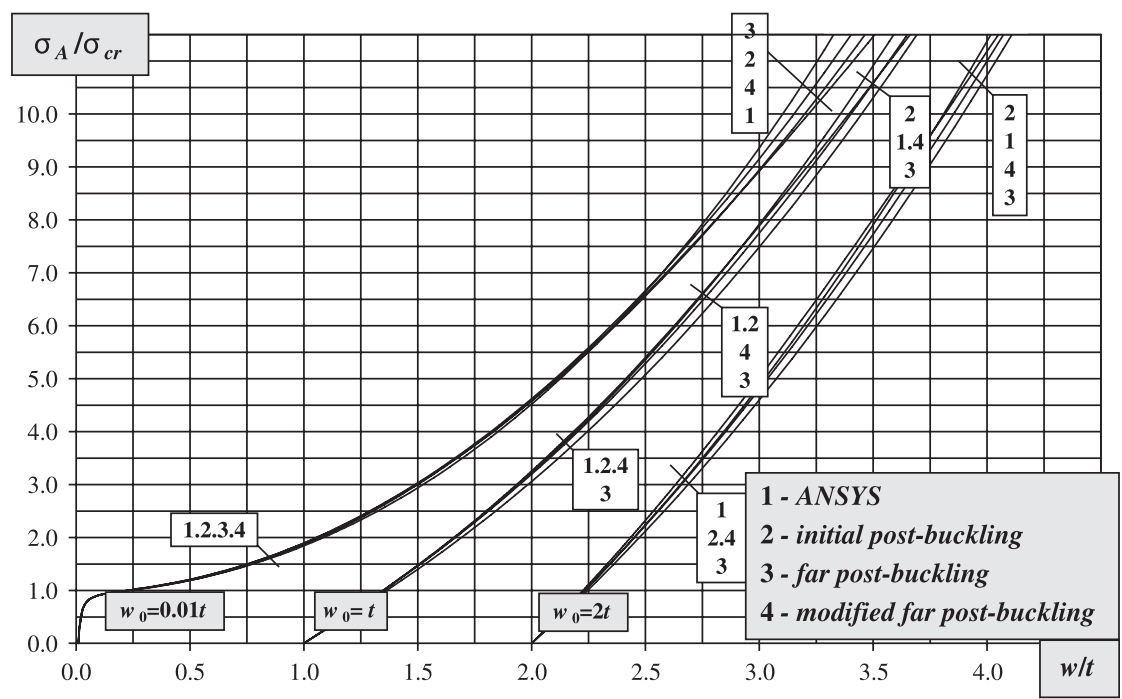

Fig. 7. Overview of selected elastic curves obtained from the FEM simulations and initial post-buckling, far post-buckling and modified far post-buckling solutions.

Table 4

Ratios's $F_{u \text {;FEM }} / F_{c r}$; the bold values represent center failure (CF) according to Mahendran's criterion [4]

\begin{tabular}{|c|c|c|c|c|c|c|c|c|}
\hline$\lambda$ & & 1.000 & 1.155 & 1.414 & 1.732 & 2.000 & 2.449 & 2.828 \\
\hline$w_{0}$ & $0.01 t$ & 0.936 & 1.020 & 1.230 & 1.555 & 1.858 & 2.384 & 2.828 \\
\hline$w_{0}$ & $0.10 t$ & 0.818 & 0.961 & 1.202 & 1.540 & 1.847 & 2.376 & 2.823 \\
\hline$w_{0}$ & $0.25 t$ & 0.745 & 0.900 & 1.164 & 1.514 & 1.827 & 2.363 & 2.812 \\
\hline$w_{0}$ & $0.50 t$ & 0.675 & 0.832 & 1.110 & 1.472 & 1.793 & 2.339 & 2.794 \\
\hline$w_{0}$ & $1.00 t$ & 0.589 & 0.744 & 1.024 & 1.395 & 1.726 & 2.289 & 2.754 \\
\hline$w_{0}$ & $1.50 t$ & 0.536 & 0.685 & 0.959 & 1.328 & 1.663 & 2.238 & 2.711 \\
\hline$w_{0}$ & $2.00 t$ & 0.499 & 0.642 & 0.908 & 1.272 & 1.605 & 2.188 & 2.669 \\
\hline
\end{tabular}

Using Eq. (42) the fictitious elastic strain $\varepsilon_{f i c ; F E M}$ corresponding to $F_{u ; F E M}$ can then be determined as

$\frac{\varepsilon_{f i c ; F E M}}{\varepsilon_{c r}}=\left(1-\frac{w_{0}}{w_{f i c ; F E M}}\right)+A_{u} \eta_{f i c ; F E M}+B_{u} \eta_{f i c ; F E M}^{2}$

Note that both the strain $\varepsilon_{f i c ; F E M}$ and the displacement $w_{\text {fic; FEM }}$ are fictitious, because they are calculated from elastic modified far post-buckling solutions, disregarding any yielding which might occur before the load $F_{u ; F E M}$ is attained. These fictitious strains and deflections thus do not correspond to the strains and deflections in the (elasto-plastic) FEM simulations at failure (see also Fig. 8).

It is interesting to compare the strains $\varepsilon_{f i c ; F E M}$ to the fictitious elastic strains $\varepsilon_{f i c ; f m y}$, which are the fictitious strains which would result in first membrane yield, if the plate would behave elastically until this first membrane yield. Thus the influence of eventual corner yield or center yield is not taken into account. The fictitious strain $\varepsilon_{f i c ; f m y}$ can be calculated by first determining $w_{\text {fic;fmy }}$ from:

$\frac{f_{y}}{\sigma_{c r}}=\left(1-\frac{w_{0}}{w_{f i c: f m y}}\right)+A_{\sigma ; A} \eta_{f i c ; f m y}+B_{\sigma ; A} \eta_{f i c ; f m y}^{2}$

where

$\eta_{f i c: f m y}=\left(\frac{w_{f i c} ; m y}{t}\right)^{2}-\left(\frac{w_{0}}{t}\right)^{2}$

Eq. (47) is derived from Eq. (43) by requiring $\sigma_{\mathrm{A}}=f_{y}$. Then the fictitious elastic strain $\varepsilon_{f i c ; f m y}$ corresponding to first membrane yield can be determined as

$\frac{\varepsilon_{f i c: f m y}}{\varepsilon_{c r}}=\left(1-\frac{w_{0}}{w_{f i c ; f m y}}\right)+A_{u} \eta_{f i c: f m y}+B_{u} \eta_{f i c: f m y}^{2}$

5.2. Empirical expressions for fictitious elastic strain at failure and accuracy of corresponding failure loads

If it is possible to develop empirical formulas to predict the fictitious strain $\varepsilon_{f i c ; u}$ at failure, then the failure load $F_{u ; \varepsilon f i c}$ can be calculated by first determining the out-of-plane deflection $w_{f i c ; u}$ from the equation

$\frac{\varepsilon_{f i c ; u}}{\varepsilon_{c r}}=\left(1-\frac{w_{0}}{w_{f i c} ; u}\right)+A_{u} \eta_{f i c ; u}+B_{u} \eta_{f i c ; u}^{2}$

where $\varepsilon_{f i c ; u}$ is the ficitious elastic strain at failure predicted by an empirical formula, and

$\eta_{f i c ; u}=\left(\frac{w_{f i c ; u}}{t}\right)^{2}-\left(\frac{w_{0}}{t}\right)^{2}$

The thus determined values for $w_{f i c ; u}$ and $\eta_{f i c ; u}$ can then be used to find the failure load, $F_{u ; \varepsilon f i c}$ :

$\frac{F_{u ; f f i c}}{F_{c r}}=\left(1-\frac{w_{0}}{w_{f i c ; u}}\right)+A_{F} \eta_{f i c ; u}+B_{F} \eta_{f i c ; u}^{2}$

In the ideal case of an "exact" empirical formula the fictitious elastic strain at failure $\varepsilon_{f i c ; u}$ will be equal to the fictitious elastic strain at failure $\varepsilon_{\text {fic; FEM }}$ determined from the FEM simulations. To assist in the development of an empirical formula to determine $\varepsilon_{f i c ; u}$, Fig. 9a shows the ratio $\varepsilon_{f i c ; F E M} / \varepsilon_{f i c ; f m y}$ as a function of the reference slenderness $\lambda$ and Fig. $9 \mathrm{~b}$ the ratio $\varepsilon_{f i c ; F E M} / \varepsilon_{y}$.

To find an empirical expression for the prediction of the fictitious strain at failure for plates failing by edge failure, both the ratios $\varepsilon_{f i c ; F E M} / \varepsilon_{f i c ; f m y}$ and $\varepsilon_{f i c ; F E M} / \varepsilon_{y}$ can be used for curve fitting. Since $\varepsilon_{y}$ is much easier to calculate than $\varepsilon_{\text {fic; fmy }}$ the ratio $\varepsilon_{\text {fic; FEM }} / \varepsilon_{y}$ will be used. It was found that for plates failing by edge failure, for a given imperfection ratio $w_{0} / t$ the relation between the ratio $\varepsilon_{f i c ; F E M}^{E F} / \varepsilon_{y}$ and the reference slenderness $\lambda$ can be approximated with good accuracy by a straight line:

$\frac{\varepsilon_{f i c ; F E M}^{E F}}{\varepsilon_{y}} \approx \frac{\varepsilon_{f i c ; u}^{E F}}{\varepsilon_{y}}=c \lambda+d$ 

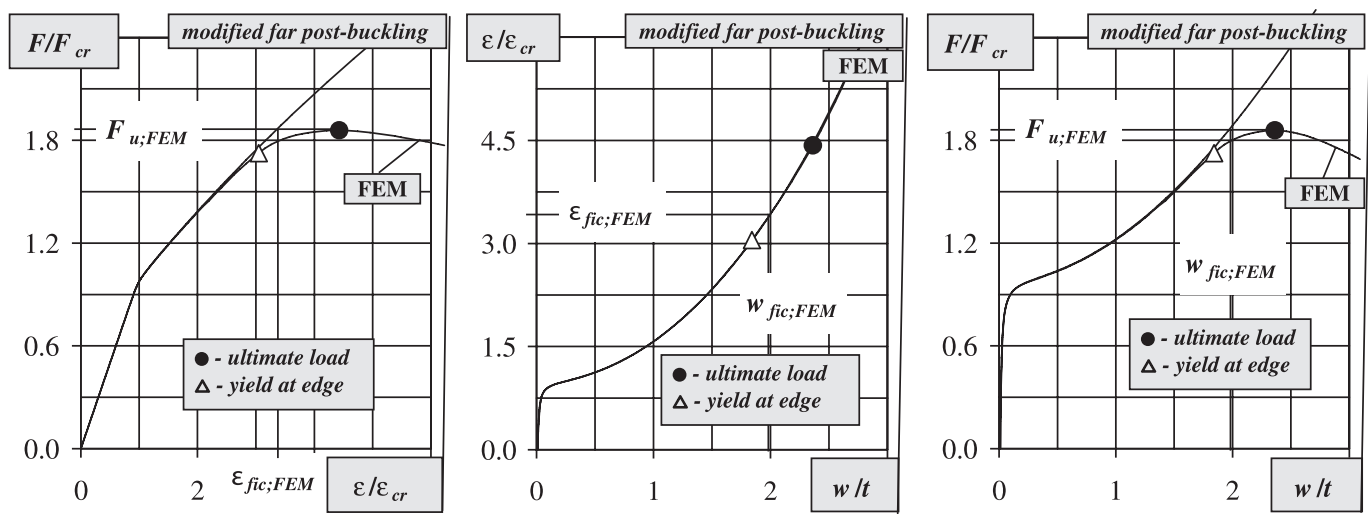

Fig. 8. Definition of fictitious elastic strain at failure (shown for $\sigma_{c r}=f_{y} / 4, w_{0}=0.01 t$ ).

a

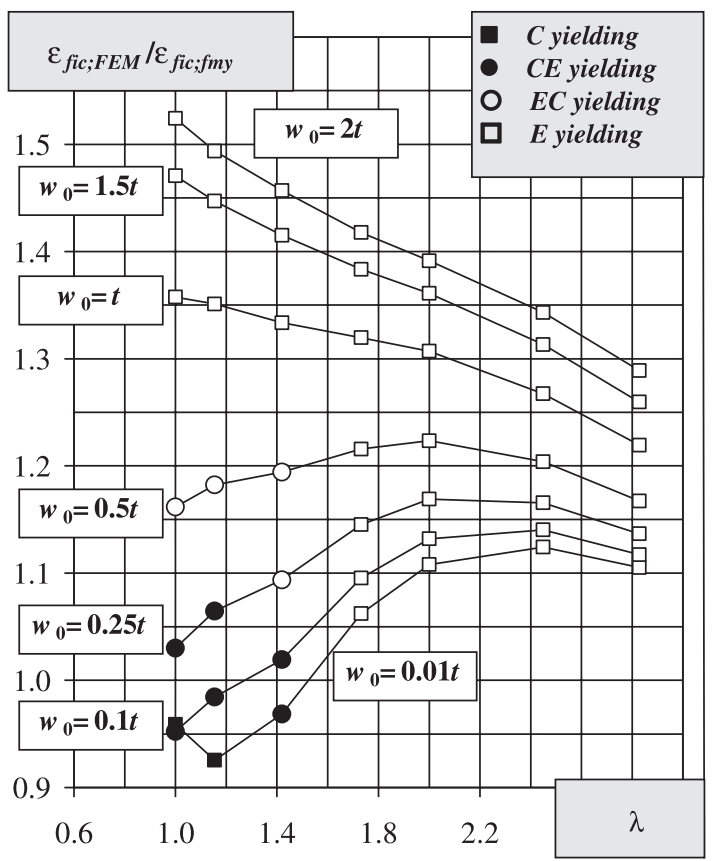

$\mathrm{b}$

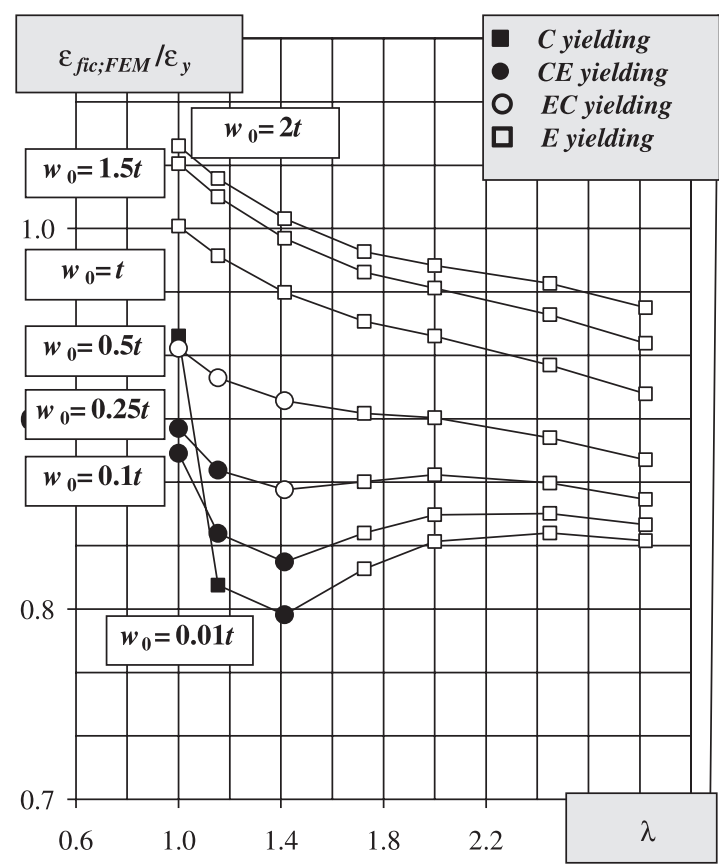

Fig. 9. (a) Ratios $\varepsilon_{f i c ; F E M} / \varepsilon_{f i c ; f m y}$ and (b) ratios $\varepsilon_{f i c ; F E M} / \varepsilon_{y}$.

where the superscript EF denotes edge failure. After determining the coefficients $c$ and $d$ for various values of the imperfection ratio $w_{0} / t$, and plotting these coefficients as a function of the reference slenderness $\lambda$, it was found that both the relation between $c$ and $\lambda$, and the relation between $d$ and $\lambda$ can also be approximated with good accuracy by a straight line, resulting in the following empirical expression for the fictitious elastic strain at edge failure [12]:

$\frac{\varepsilon_{f i c ; u}^{E F}}{\varepsilon_{y}}=\frac{w_{0}}{t}(0.139-0.029 \lambda)+0.844$

Figs. 9a and b show that for plates failing by center failure there is not such a simple linear relation between the ratio $\varepsilon_{\text {fic } F \text { FEM }}^{C F} / \varepsilon_{f i c ; f m y}$ or $\varepsilon_{\text {fic:FEM }}^{C F} / \varepsilon_{y}$ and the reference slenderness $\lambda$, where the superscript $\mathrm{CF}$ denotes center failure. Fortunately the accuracy of the prediction of the ultimate load is not very sensitive to errors in the assumed fictitious elastic strain at failure. Taking

$\varepsilon_{f i c ; u}^{C F}=\varepsilon_{f i c: f m y}$

gives reasonable results for plates failing by center failure.
Table 5 shows the ratios $F_{u ; \varepsilon f i c}^{C F} / F_{u ; F E M}$ and $F_{u ; \varepsilon f i c}^{E F} / F_{u ; F E M}$, where $F_{u ; f i c}^{C F}$ and $F_{u ; f f i c}^{E F}$ are the failure loads calculated with the fictitious strain method, taking $\varepsilon_{f i c ; u}=\varepsilon_{f i c ; u}^{C F}$ (see Eq. (54)) respectively $\varepsilon_{f i c ; u}=\varepsilon_{f i c ; u}^{E F}$ (see Eq. (55)).Taking $\varepsilon_{f i c ; u}=\varepsilon_{f i c ; u}^{C F}=\varepsilon_{f i c: f m y}$ as done in the effective width method, paradoxically results in reasonable accurate strength predictions for plates failing by center failure, but very conservative predictions for plates failing by edge failure. For plates failing by edge failure, taking $\varepsilon_{f i c ; u=} \varepsilon_{f i c ; u}^{E F}$ instead of $\varepsilon_{f i c ; u=} \varepsilon_{f i c ; u}^{C F}=\varepsilon_{f i c ; f m y}$, results in a much improved strength prediction. Surprisingly, $\varepsilon_{f i c ; u=} \varepsilon_{f i c ; u}^{E F}$ gives also very good results for plates failing by center failure, except for the plate with $\lambda=1$ and $w_{0} / t=0.01$. This suggests it might be possible to improve the strength predictions by modifying the criterion to determine whether $\varepsilon_{f i c ; u}^{C F}$ or $\varepsilon_{f i c ; u}^{E F}$ should be used for the strength prediction, for instance by modifying the coefficients in Mahendran's formula (Eq. (9)). One can also argue that initial imperfection ratios $w_{0} / t=0.01$ are so small that they will not occur in practice for plates with $\lambda \geqslant 1$ (see also Section 6.1), and that for all practical imperfection ratios $w_{0} / t>0.1, \varepsilon_{f i c ; u}^{E F}$ can be used for strength predictions. 
Table 5

Ratios $F_{u ; f i c}^{C F} / F_{u ; F E M}$ and $F_{u ; f i c}^{E F} / F_{u ; F E M}$; the bold values represent center failure (CF) according to Mahendran's criterion [4]

\begin{tabular}{|c|c|c|c|c|c|c|c|c|c|c|c|c|c|c|}
\hline \multirow[t]{2}{*}{$w_{0}$} & \multicolumn{7}{|c|}{$\begin{array}{l}F_{u ; \varepsilon f i c}^{C F} / F_{u ; F E M} \\
\sigma_{c r} / f_{y}\end{array}$} & \multicolumn{7}{|c|}{$\begin{array}{l}F_{u ;: f i c}^{E F} / F_{u ; F E M} \\
\sigma_{c r} / f_{y}\end{array}$} \\
\hline & 1 & $3 / 4$ & $1 / 2$ & $1 / 3$ & $1 / 4$ & $1 / 6$ & $1 / 8$ & 1 & $3 / 4$ & $1 / 2$ & $1 / 3$ & $1 / 4$ & $1 / 6$ & $1 / 8$ \\
\hline $0.01 t$ & 1.03 & 1.05 & 1.02 & 0.97 & 0.94 & 0.93 & 0.94 & 0.90 & 1.02 & 1.03 & 1.02 & 1.01 & 1.00 & 1.01 \\
\hline $0.10 t$ & 1.04 & 1.02 & 0.99 & 0.95 & 0.93 & 0.92 & 0.93 & 0.98 & 1.01 & 1.02 & 1.01 & 1.00 & 1.00 & 1.00 \\
\hline $0.25 t$ & 0.98 & 0.97 & 0.94 & 0.92 & 0.90 & 0.91 & 0.92 & 0.98 & 1.00 & 1.00 & 1.00 & 1.00 & 1.00 & 1.00 \\
\hline $0.50 t$ & 0.89 & 0.89 & 0.88 & 0.87 & 0.87 & 0.88 & 0.91 & 0.97 & 0.98 & 0.99 & 0.99 & 0.99 & 0.99 & 1.00 \\
\hline $1.00 t$ & 0.76 & 0.77 & 0.79 & 0.80 & 0.82 & 0.84 & 0.87 & 0.96 & 0.97 & 0.98 & 0.98 & 0.99 & 0.99 & 0.99 \\
\hline $1.50 t$ & 0.70 & 0.72 & 0.74 & 0.76 & 0.78 & 0.81 & 1.26 & 0.98 & 0.99 & 1.00 & 1.00 & 1.00 & 0.99 & 0.99 \\
\hline $2.00 t$ & 0.67 & 0.69 & 0.71 & 0.74 & 0.76 & 0.80 & 0.83 & 1.02 & 1.02 & 1.03 & 1.03 & 1.02 & 1.01 & 1.00 \\
\hline
\end{tabular}

\section{Discussion}

\subsection{Effective width method}

As Rhodes [1] noted, the term effective width has been used in the literature to describe different effects. In this paper, a distinction will be made between an effective width for maximum membrane stress, an effective width for strength, and an effective width for stiffness. Following Rhodes [1] the effective width $b_{e f ; \sigma A}$ for maximum membrane stress is defined as that width of fully effective (i.e. unbuckled) plate which sustains the same maximum membrane stress $\sigma_{\mathrm{A}}$ as the buckled plate under a given load:

$b_{e f ; \sigma A}=b \frac{\sigma}{\sigma_{\mathrm{A}}}$

The effective width $b_{e f ; \varepsilon}$ for stiffness can be defined as that width of unbuckled plate which sustains the same average strain $\varepsilon$ as the buckled plate for a given load:

$b_{e f ; \varepsilon}=b \frac{\sigma}{E \varepsilon}$

If it is assumed that the ultimate load which a plate can withstand is very close to that which causes first membrane yield, the failure load can be calculated from the effective width for maximum membrane stress $b_{e f ; \sigma_{A}}$ as

$F_{u}=b_{e f(\sigma A=f y)} t f_{y}$

For that reason Rhodes [1] called the effective width for maximum membrane stress the effective width for strength. If one recognizes that a plate does not necessarily fail at a load close to the load causing first membrane yield, it is more appropriate to define an effective width $b_{e f ; \sigma A}$ for strength as

$b_{e f ; F u}=\frac{F_{u}}{t f_{y}}$

This definition implies that the assumption that the edges of the plate start yielding at failure is not integral to the effective width for strength concept.

The modified far post-buckling formulas and empirical expressions for fictitious elastic strains at failure can now be used to determine the above-defined effective widths as explicit functions of the initial imperfections, by rewriting Eqs. (56), (57) and (59) as

$\frac{b_{e f ; \sigma A}}{b}=\frac{\sigma}{\sigma_{\mathrm{A}}} \frac{\sigma_{c r}}{\sigma_{c r}}=\frac{\sigma}{\sigma_{c r}} \frac{\sigma_{c r}}{\sigma_{\mathrm{A}}}$

$\frac{b_{e f ; \varepsilon}}{b}=\frac{\sigma}{E \varepsilon} \frac{\sigma_{c r}}{\sigma_{c r}}=\frac{\sigma}{\sigma_{c r}} \frac{\varepsilon_{c r}}{\varepsilon}$

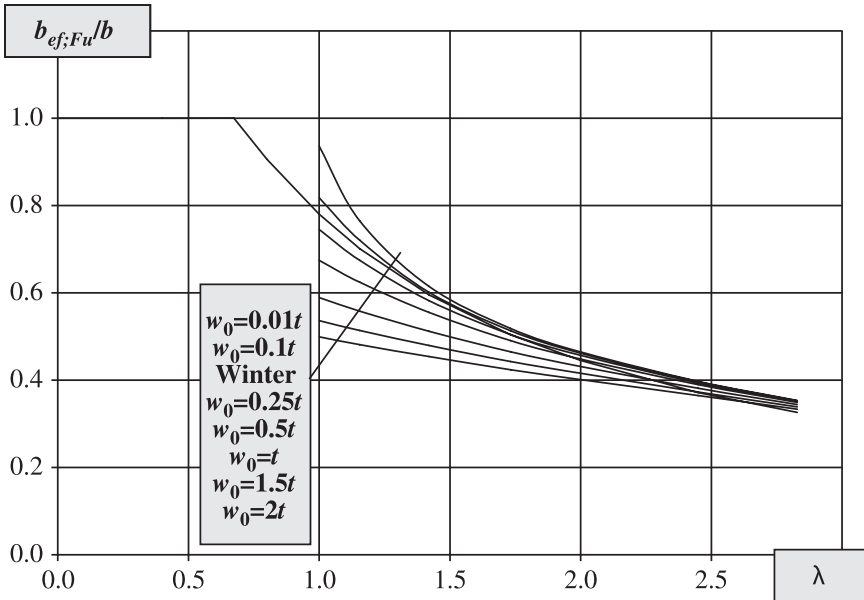

Fig. 10. Effective width for strength determined from FEM solutions compared to effective width according to Winter formula.

$\frac{b_{e f ; F u}}{b}=\frac{F_{u}}{F_{y}} \frac{\sigma_{c r}}{\sigma_{c r}}=\frac{F_{u}}{F_{c r}} \frac{\sigma_{c r}}{f_{y}}$

where

$F_{y}=b t f_{y}$

Fig. 10 shows the effective widths ratios $b_{e f ; F u} / b$ determined from the finite element simulations taking $F_{u}=F_{u ; F E M}$, using Eq (62), for various values of imperfections $w_{0} / t$. In Fig. 10 also the Winter formula is shown:

$\frac{b_{e f}}{b}=\frac{1}{\lambda}\left(1-\frac{0.22}{\lambda}\right)$

By determining the points of intersection of the Winter formula, and the effective width curves explicitly depending on initial imperfections, it can be seen what initial imperfections result in the same strength as the Winter formula (at least for simply supported square plates with initial imperfections in the shape of the first buckling mode). These initial imperfections increase with increasing reference slenderness $\lambda$, from imperfection ratios $w_{0} / t$ between 0.1 and 0.25 for plates with a reference slenderness $\lambda$ equal to 1 , to imperfection ratios $w_{0} / t$ larger than 2 for plates with a reference slenderness $\lambda$ larger than about 2.5 .

\subsection{Importance of changes in the deflected form}

The difference between initial post-buckling and far postbuckling behavior will become significant for plates with a reference slenderness $\lambda$ larger than about 2. From Table 4 it can 
be seen that these plates fail at ratios $F / F_{c r}$ of about 1.8 for small imperfections. For larger imperfections this ratio decreases, but for larger imperfections the modified far post-buckling solution starts to deviate from the initial post-buckling solution at smaller loads. Of course one can also derive expressions for the fictitious strain at failure using initial post-buckling equations. This would result in simpler equations to determine the ultimate strength, especially since it would then be possible to derive an explicit solution for the out-of-plane deflection corresponding to the fictitious elastic strain at failure [12].

\section{Conclusions}

This paper clarifies the occurrence and character of different failure modes in uniformly compressed, square simply supported plates with stress-free longitudinal edges, depending on the slenderness and initial imperfections of the plate. It has been shown how relatively simply, elastic modified far post-buckling solutions and empirically derived expressions for the fictitious elastic strain at failure can be used to obtain accurate strength predictions. The proposed method can be regarded as a modification of the effective width method for strength described by Rhodes [1], which is based on elastic initial post-buckling solutions, and the assumption that $\varepsilon_{f i c ; u}=\varepsilon_{f i c ; f m y}$. The proposed method enables the determination of the effective width for strength with an explicit influence of initial imperfections. It is shown that the effective width for strength may be different from the effective width for maximum membrane stress, and that the assumption that the edges of the plates start yielding at failure is not integral to the effective width for strength concept.

For the prediction of the fictitious elastic strain at failure a distinction has been made between plates failing by edge failure and plates failing by center failure. Which failure mode occurs can be determined from Eq. (9). Taking $\varepsilon_{f i c ; u}=\varepsilon_{\text {fic:u }}^{C F}=\varepsilon_{\text {fic:fmy }}$ results in reasonable strength predictions for plates failing by center failure but very conservative strength predictions for plates failing by edge failure. For plates failing by edge failure a much better strength prediction can be obtained by taking $\varepsilon_{f i c ; u}=\varepsilon_{f i c ; u}^{E F}$ where $\varepsilon_{f i c ; u}^{E F}$ is given by Eq. (54). Taking $\varepsilon_{f i c ; u}=\varepsilon_{f i c ; u}^{E F}$ gives also good results for plates failing by center yielding, except for plates with a reference slenderness $\lambda$ close to 1 and very small imperfections. Based on a comparison of FEM solutions with strength predictions by Winter's effective width formula it can be concluded that for plates with $\lambda \geqslant 1$ and practical imperfection rations $\left(w_{0} / t>0.1\right)$, the fictitious elastic strain $\varepsilon_{f i c ; u}^{E F}$ can be used for strength predictions, regardless whether failure will occur by edge or center failure.

Since the study was limited to square simply supported plates with longitudinal edges free to wave in plane subjected to uniform compression, further research is necessary to determine whether the proposed fictitious elastic strain method is also applicable to plates with other geometries, loading and boundary conditions.

\section{Acknowledgments}

This research is part of an Aspasia program and was supported by the Technology Foundation STW, applied science division of NWO and the technology program of the Ministry of Economic Affairs.

\section{References}

[1] Rhodes J. Effective widths in plate buckling. In: Rhodes J, Walker AC, editors. Developments in thin-walled structures-1. London, England: Applied Science Publishers; 1982. p. 119-58.

[2] Calladine CR. The strength of thin plates in compression. In: Dawe DJ, Horsinton RW, Little AG, editors. Aspects of the analysis of plate structures, a volume in honour of Wittrick. Oxford, England: Clarendon Press; 1985. p. 269-91.

[3] Bakker MCM, Rosmanit M, Hofmeyer H. Elastic post-buckling analysis of compressed plates using a two-strip model. Thin-Walled Struct 2007;45: 502-16.

[4] Mahendran M. Local plastic mechanisms in thin steel plates under in-plane compression. Thin-Walled Struct 1997;27:245-61.

[5] Murray NW. Introduction to the theory of thin-walled structures. Oxford, England: Clarendon Press; 1986.

[6] Hofmeyer H, Kerstens JGM, Snijder HH, Bakker MCM. New prediction model for failure of steel sheeting subjected to concentrated load (web crippling) and bending. Thin Walled Struct 2001;39:773-96.

[7] Little GH. The collapse of rectangular steel plates under uniaxial compression. Struct Eng 1980;58B:45-61.

[8] Bakker MCM, Rosmanit M, Hofmeyer H. Elastic post-buckling behavior of uniformly compressed plates. In: Laboube RA, Yu WW, editors. Recent research and developments in cold formed steel design and construction Proceedings of the 18th international specialty conference. Rolla, MI, USA: University of Missouri Rolla; 2006. p. 1-15.

[9] Walker AC, Murray NW. Analysis for stiffened plate panel buckling. Civil engineering research report no. 2/1974. Monash University, 1974.

[10] Williams DG, Walker AC. Explicit solutions for the design of initially deformed plates subjected to compression. Proc Inst Civil Eng 1975(Part 2):763-87.

[11] Rosmanit M, Bakker MCM. Report on elastic post-buckling analysis of compressed plates using a two-strip model. Research report 0-2007.05, Technische Universiteit Eindhoven, Department of Architecture, Building and Planning, Structural Design Group, The Netherlands, 2007.

[12] Rosmanit M, Bakker M.C.M. Report on prediction of the elasto-plastic postbuckling strength of uniformly compressed plates from the fictitious elastic strain at failure. Research report 0-2007.23, Technische Universiteit Eindhoven, Department of Architecture, Building and Planning, Structural Design Group, The Netherlands, 2007. 